\title{
Learning from conflict and disaster in the Eastern Mediterranean region
}

Political instability and natural disasters in the region have been responsible for many humanitarian crises over the past two decades, and there is little likelihood that the situation will improve in the future. Recent and ongoing crises in Lebanon, Somalia, Sudan, Afghanistan, Iraq, and the Occupied Palestinian Territory pose huge difficulties, as the three personal perspectives of experience on the front line by Hill and colleagues, Van de Pas, and Al Sheibani and colleagues underline. In the first article Musani and Shaikh argue that more investment should be made in preparing for disaster and attempting to reduce the vulnerability of communities at risk.

\section{Preparedness for humanitarian crises needs to be improved}

Altaf Musani, Irshad Shaikh

An estimated 4.1 billion people were affected by natural disasters, including earthquakes, floods, landslides, and drought, during 1984-2003. ${ }^{1}$ Over 160 countries experienced such disasters in 2004, and these, together with industrial incidents such as chemical spills, resulted in over 350000 deaths. $^{2}$ One of the most common human generated disasters, however, is conflict. ${ }^{3}$ In the past decade there have been over 38 major conflicts globally, with $70 \%$ of the victims being civilians. The percentage of civilians killed and injured in conflict has been increasing, and is currently around $90 \% .{ }^{4}$

\section{Effect of conflict in Eastern Mediterranean}

In the World Health Organization's Eastern Mediterranean region, Afghanistan, Iraq, Lebanon, the Occupied Palestinian Territory, Somalia, and Sudan are currently struggling to deal with prolonged conflicts. The United Nations emergency relief coordinator, Jan Egeland, described the conflicts in Somalia, Sudan, and the Occupied Palestinian Territory as the three most challenging current humanitarian situations (box). ${ }^{5}$ They have affected 10 million people, of whom 6.5 million have been displaced from their homes and around 200000 have died. ${ }^{6}$ The long history of ethnic, religious, and geographic tensions in these areas make it unlikely that the health and humanitarian problems are going to decrease.

Poor and marginalised members of society are most often exposed to disasters and least capable of coping when they occur. ${ }^{7}$ The infrastructure of cities such as Karachi, Lahore, Cairo, Tehran, Sanaa, Kabul, Mogadishu, Hargeisa, Khartoum, and Baghdad can no longer cope with the growing populations. Hundreds of thousands of people live in slums or low income housing. These homes are relatively unsafe because they are of poor structural quality or in high risk locations, which is likely to compound future emergencies.

\section{Role of WHO}

In 2001 WHO set up a dedicated emergency and humanitarian action unit in Cairo to provide technical and public health expertise and material support to the 22 ministries of health in the Eastern Mediterranean region, sister UN agencies, Red Crescent and Red

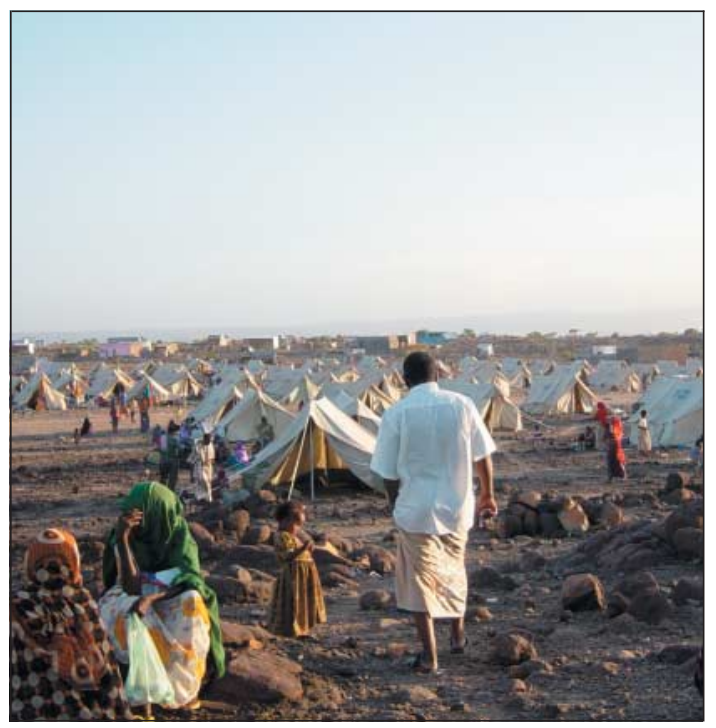

Emergency

Preparedness and Humanitarian Action, World Health

Organization

Regional Office for the Eastern Mediterranean, PO Box 7608 , Nasr City 11371,

Cairo, Egypt

Altaf Musani regional adviser Irshad Shaikh medical epidemiologist Correspondence to: A Musani: musania@ emro.who.int

Cross societies, and other non-governmental and academic partners. Recently it has linked with the other regional UN agencies to develop a common mechanism for sharing information and collaborating on joint missions. Since the establishment of the Inter Agency Standing Committee in 1992, an interagency forum for coordination, policy development, and decision making (www.humanitarianinfo.org/iasc), WHO has become the lead agency for health.

\section{Put to the test in Lebanon}

A WHO emergency team was dispatched to Beirut within a week of the crisis in Lebanon earlier this year. The team included public health, logistics, security, environmental health, and epidemiology experts to implement a humanitarian programme developed to address both preventive and curative health activities (see bmj.com).

Lebanon initially received a surge of relief supplies and assistance from international humanitarian partners. The national Lebanese network of organisations and international partners were successful in reaching the most vulnerable people in southern Lebanon and 


\section{Current effects of conflict (data from www.reliefweb.int)}

$70 \%$ of Palestinians in the Gaza Strip cannot feed themselves without humanitarian assistance

Around one million children in the south of Somalia are living in a state of emergency, and a fifth of children under 5 years old are malnourished Renewed fighting in south Darfur has forced 10000 to flee their homes

those displaced in temporary shelters. Many medical and other relief staff braved frontlines to provide essential supplies and transport. The humanitarian space allowing the safe passage of supplies and humanitarian aid workers to affected areas was not systematically upheld during the crisis. Access had to be negotiated on a case by case basis, which severely delayed the provision of much needed water, shelter, food, and medicines to people stranded in villages and towns in the south of the country.

The WHO team implemented its health cluster programme and helped coordinate the emergency response. This included taking steps to prevent duplication of vital activities such as immunisation of children against polio and measles, distribution of essential medicines and fuel to hospitals, provision of water and hygiene kits in displaced camps, and establishing a disease early warning system to detect and rapidly respond to any major outbreaks.

After the ceasefire, the ministry of health, WHO, and others managed to carry out a rapid assessment of more than 400 health facilities areas in the south. A quarter of health facilities were not functioning because of physical damage, lack of staff, or lack of access. Twelve buildings were totally destroyed and 38 severely damaged. Fuel to run hospital generators, oxygen, and medicines, including those for chronic diseases, were identified as acute needs. ${ }^{8}$

The new and emerging humanitarian priorities include provision of primary healthcare services; management of chronic disease; control of outbreaks of communicable disease; environmental health and provision of safe water to the rapidly returning population; mitigation of immediate threats posed by unexploded ordnance, primarily in the south of the country; and strengthening of the UN humanitarian hubs. Initial UN assessment reports indicate that over 100 people have been injured and about 14 killed by cluster bombs in southern Lebanon since the end of the hostilities. ${ }^{9}$

\section{Learning from experience}

Several problems were encountered during the acute phase of the conflict, and these can be used to inform future best practice for WHO response teams. The problems included:

\section{Factors that may compound or contribute to future emergencies}

- Urbanisation

- Health disparities and economic inequities

- Lack of environmental and ecological safeguards

- Food and water insecurities

- Population migration due to conflict, lack of food and water, or political, economic, and environmental problems
- Difficulty obtaining sustained financial resources to initiate humanitarian health assistance activities

- Existing development oriented programmes were not able to adapt suddenly to provide an emergency response

- The massive displacement of people and then returnees made it difficult to plan ahead effectively

- Coordination of health partners (previously rolled out in major emergencies) was difficult as many of the local organisations had established ad hoc operational mechanisms

- If the bombing had continued and displaced people remained in temporary shelter the poor hygiene would probably have led to a larger scale health crisis

- Security constraints made it difficult for UN staff to reach the people in need

- International humanitarian law and the Geneva convention were not upheld, particularly the bombing of the health infrastructure and impeding access of health workers and ambulances.

Previous emergencies in the region have also produced valuable lessons (see table on bmj.com).

\section{Preparing for disaster}

Disaster management has focused on the immediate response to the event and humanitarian assistance. Few funds have been allocated to reduce vulnerability by preparing for disaster. ${ }^{10}$ This is unsurprising as the benefits of investment in preparedness accrue only in the future.

The risk factors that are likely to contribute or compound the damage of future disasters in the region continue to grow (box). ${ }^{11}$ This makes better preparedness crucial. Critical issues such as the "defence of urban public health infrastructure, sanitation and access to water are not being addressed in existing education, training, research and management forums."

\section{Making action evidence based}

It is wrong to assume that the disaster response has been, and will be, based on scientific evidence. ${ }^{12}$ Most emergency preparedness and planning is based on conventional wisdom rather than on systematically collected evidence. ${ }^{13}$ The Humanitarian Response Review commissioned by the United Nations identified serious gaps in the current international humanitarian action. ${ }^{14}$ Although pioneers such as the Sphere Project (www.sphereproject.org) are beginning to tackle these gaps, a lot more work is required. ${ }^{15}$

The region needs to build up more expertise in natural hazards and risk reduction, which has been dominated by academics and research centres from the North. The region also needs to develop better way of disseminating research evidence and best practice guidelines to "end users," who often don't have access to scientific journals.

Disasters can and have erased years of development in a matter of hours. Reducing the risks through preparation needs to be recognised as both a humanitarian and development issue, fully integrated into development policies and plans. Building local capacities is one of the most cost effective ways to improve the quality of national response and the external interventions. ${ }^{16}$ More effective prevention and preparedness 


\section{Summary points}

The scale and effect of conflict and other disasters in the Eastern Mediterranean region are likely to increase

Humanitarian agencies need to learn from their experience

The response to disaster needs to be informed by good evidence

More investment is needed to make communities better prepared for disaster and less vulnerable

strategies would save not only billions of dollars but thousands of lives, and funds currently spent on intervention and relief could be devoted to enhancing equitable and sustainable development, which would further reduce the risk of war and disaster. ${ }^{17}$ Recent resolutions endorsed by the World Health Assembly of WHO and the Regional Committee of the Eastern Mediterranean region also emphasise preparedness along with response and are the guiding force behind a number of new initiatives (see bmj.com).

Contributors and sources: AM and IS have been extensively involved in emergency preparedness and response related health policy and planning, operations, and research and as first responders in the humanitarian/complex emergencies in the Eastern Mediterranean region. This article is the product of their observations from the field, discussions with peers, review of relevant documents, and on-going capacity building initiatives at the Regional Office for the Eastern Mediterranean.
Both authors gathered data for the article. AM wrote the first draft and IS made revisions for important intellectual content. $\mathrm{AM}$ is the guarantor.

Competing interests: None declared.

1 Hazards of nature, risks to development: an IEG evaluation of World Bank assistance for natural disasters. Washington, DC: World Bank, 2006.

2 EM-DAT: The OFDA/CRED International Disaster Database www.emdat.net)

3 Burkel FM. Complex humanitarian emergencies: A review of epidemiological and response models. J Postgrad Med 2006;52:110-9.

4 Garfield RM, Neugut AI. The human consequences of war. In: Levy BS, Sidel VW, eds. War and public health. Oxford: Oxford University Press, 1997:27-38.

5 United Nations. Press conference by UN emergency relief coordinator, 11 July 2006. www.un.org/News/briefings/docs/2006/060711_Egeland. doc.htm 2006. www.un.org/News/

6 Guha-Sapir D, Degomme O. Darfur: counting the deaths (2). What are the trends? Brussels: Centre for Research on the Epidemiology of Disasters, Université Catholique de Louvain, 2005.

7 Rautela P. Risk management for vibrant economic growth and sustained development. Disaster Prev Manage 2006;15:585-97.

8 ReliefWeb. Lebanon crisis flash appeal 24 July 2006. www.reliefweb.int/rw/ rwb.nsf/db900SID/KHII-6RZ7Z3?OpenDocument (accessed 5 Oct 2006).

9 United Nations Office for the Coordination of Humanitarian Affairs. Lebanon response: OCHA situation report No 39, Sep 2006. www. reliefweb.int/rw/rwb.nsf/db900SID/KHII-6U332L?OpenDocument reliefweb.int/rw/rwb.nsf
(accessed 28 Sep 2006).

10 Alexander B, Chan-Halbrendt C, Salim W. Sustainable livelihood consid0 Alexander B, Chan-Halbrendt C, Salim W. Sustainable livelihood consid-
erations for disaster risk management: implications for implementation of the government of Indonesia tsunami recovery plan. Disaster Prev Manag 2006;15:31-50.

11 Sengezer, B, Koc E. A critical analysis of earthquakes and urban planning in Turkey. Disasters 2005;2992:171-94.

12 Noji EK. Disasters: introduction and state of the art. Epidemiol Rev 2005;27:3-8.

13 ProVention Consortium. Expanding research and learning. www. proventionconsortium.org/?pageid $=14$ (accessed 9 Oct 2006).

14 UN Office for Coordination of Human Affairs. Humanitarian response review. Geneva: OCHA, 2005.

15 WHO. Report of a workshop on tracking health performance and humanitarian outcomes, Geneva, 1-2 December 2005. Geneva: WHO, 2006.

16 Disease Control Priorities Project. Disease control priorities in developing countries. Washington, DC: World Bank, Oxford University Press, 2006.

17 Annan K. Facing the humanitarian challenge: towards a culture of prevention. Geneva: UN, 2004.

doi $10.1136 /$ bmj.38994.548125.94

\title{
Hope and despair over health in Gaza
}

\author{
Allan G Hill, Cari Jo Clark, Ismail Lubbad, Claude Bruderlein
}

The Israeli re-invasion of Gaza this July has redrawn the world's attention to the dire straits of the population living in the Gaza Strip. There, within an area the size of the Isle of Wight, 1.4 million people live without free access to the outside world. Contrary to international hopes, the Israeli decision to withdraw from Gaza in September 2005 has led to increasingly tight control over the movement of goods and people. The destruction of the Gaza power station in addition to the damage to bridges, roads, and other infrastructure can only worsen the plight of Gazans in the coming months.

\section{Untenable dependence on aid}

But the current crisis has been looming since well before the renewed hostilities this July. Despite the massive investment by Western donors in public infrastructure over the past decade, the Gaza Strip was never designed to sustain a viable and developed society. For the past 50 years it has hosted the largest concentration of refugees in the world, maintained in a state of dependency on international assistance at the highest levels per head since the second world war. The Oslo peace process was launched to tackle this structural dependency, hoping to transform Gaza into a self sustaining and open economy based on links to the West Bank and beyond.

Gaza is the first region in the Occupied Palestinian Territory to experience the effect of Oslo's demise in the form of major threats to health and human security. Its population will double in the next 22 years. ${ }^{1}$ Water resources are on the verge of exhaustion; residential overcrowding is severe, with several generations living in the same house; schools are running on two to three shifts; and unemployment and poverty have both doubled in the past five years. In $2004,36 \%$ of men and $33 \%$ of women were unemployed or underemployed in Gaza; daily wage rates were less than half those in Israel and the settlements; and $27 \%$ of school aged children were at work rather than attending school. For the last quarter of 2005 , the monthly income of $63 \%$ of households fell below the poverty line and $43 \%$ were living in deep poverty. $^{2}$

Aid dependency is extreme. ${ }^{3}$ Before the recent cuts, the value of government assistance per household had risen to $\$ 188$ ( $£ 100 ; € 148$ ), with an additional $\$ 42$ provided by the United Nations Relief and Works Agency
Harvard Center for Population and Development Studies, 9 Bow Street, Cambridge MA 02138, USA Allan G Hill Andelot professor of demography

Harvard Program on Humanitarian Policy and Conflict Research, Cambridge MA Cari Jo Clark research coordinator Ismail Lubbad research coordinator, Gaza Claude Bruderlein director

Correspondence to: A G Hill ahill@ hsph.harvard.edu 